\title{
ALGORITMA DAN PEMROGRAMAN KARTU PERUBAHAN RENCANA STUDI (KPRS) MAHASISWA JURUSAN MATEMATIKA UNAND DENGAN VISUAL BASIC 6.0

\author{
ALGORITHMS AND PROGRAMMING CARD CHANGES STUDY PLAN \\ (KPRS) UNAND MATH MAJOR STUDENTS WITH VISUAL BASIC 6.0
}

\author{
Yessy Yusnita \\ Pendidikan Matematika, FKIP, Universitas Riau Kepulauan Batam \\ yessyyusnita14@gmail.com
}

\begin{abstract}
Abstrak
Penelitian ini bertujuan membuat form Kartu Perubahan Rencana Studi (KPRS) serta algoritma form KPRS tersebut yang disesuaikan dengan format form Universitas Andalas. Sering terjadinya keterlambatan penerimaan dan adanya kesalahan-kesalahan data pada Kartu Rencana Studi (KPRS) dari Pusat Komputer (PUSKOM) Universitas Andalas, menyebabkan proses akademik jurusan Matematika berjalan kurang lancar. Sementara bagi mahasiswa yang akan mengurus kesalahan-kesalahan tersebut, sering mengalami kesulitan. Oleh karena itu KPRS seorang mahasiswa perlu didata dan disusun sedemikian rupa oleh jurusan Matematika, agar proses akademik dijurusan Matematika dapat berjalan dengan baik dan lancar. Program atau algoritma untuk pembuatan form dibuat dengan menggunakan Visual Basic 6.0. Data yang diinput seperti No.BP mahasiswa dan nama dosen pembimbing dalam pembuatan algoritma form KPRS tersebut, dibatasi pada data mahasiswa Non Reguler 2005 dan data dosen jurusan matematika Universitas Andalas. Pada form dibuat menu utama seperti Pengolahan Data, Tampilan dan Programmer. Menu pilihan dapat dipilih dari menu utama dan diklik untuk menampilkan form lainnya.
\end{abstract}

Kata Kunci: Algoritma dan Program Visual Basic 6.0, Kartu Perubahan Rencana Studi (KPRS)

\begin{abstract}
The aim of this study is to create the form of study change planning card (KPRS) and algorithm of KPRS form which adapted from templete of Universitas Andalas form. The frequent occurrence of delays in the receipt and the errors of data on Study Plan Card (KPRS) of the Computer Center (PUSKOM) Andalas University, Department of Mathematics led to the academic process runs less smoothly. As for the students who will take care of these errors, often have difficulty. Therefore KPRS a student needs to be recorded and compiled in such a way by the Department of Mathematics, Academic Honors in Mathematics that process can run smoothly. input data for the form is student ID and lecturer name. The scope of data is Non-reguler student 2005 and math lecturer of Andalas University. There is main menu that have three sub menu for processing, displaying and programming the data. Those sub menu can be selected by clicking it to display the information.
\end{abstract}


Keywords: Algorithm and Microsoft Visual Basic 6.0, study change planning card

\section{PENDAHULUAN}

Sering terjadinya keterlambatan penerimaan dan adanya kesalahan-kesalahan data pada Kartu Rencana Studi (KPRS) dari Pusat Komputer (PUSKOM) Universitas Andalas, menyebabkan proses akademik jurusan Matematika berjalan kurang lancar. Sementara bagi mahasiswa yang akan mengurus kesalahan-kesalahan tersebut, sering mengalami kesulitan. Oleh karena itu KPRS seorang mahasiswa perlu didata dan disusun sedemikian rupa oleh jurusan Matematika, agar proses akademik dijurusan Matematika dapat berjalan dengan baik dan lancar. Mengingat hal tersebut, jurusan Matematika perlu membuat program untuk form KPRS sendiri, dimana from tersebut dapat dibuat dengan menggunakan Visual basic 6.0

Visual Basic 6.0 merupakan bahasa pemrograman yang banyak digunakan pada beberapa tahun terakhir ini, bila dibandingkan dengan bahasa pemrograman lainnya. Hal ini disebabkan karena kemudahan dalam penggunaan serta tampilannya yang menarik. Oleh karena belum terdapatnya program untuk pembuatan form KPRS di jurusan Matematika, maka dengan menggunakan bahasa pemrograman Visual basic 6.0 dapat dibuat dan form tersebut dapat dipergunakan oleh jurusan Matematika.

\section{LANDASAN TEORI}

\section{Pengenalan Visual Basic 6.0}

Visual Basic 6.0 merupakan salah satu bahasa pemrograman yang bekerja dalam lingkup microsoft Windows. Bahasa pemrograman Visual basic 6.0 pada dasarnya mempunyai konsep yang sama dengan bahasa pemrograman yang lainnya seperti Basic, C++ dan Pascal meskipun sintaks dari tiap-tiap bahasa tidak sama. Lompatan besar Visual Basic6.0 adalah kemampuannya untuk memanfaatkan windows.

Bahasa ini tidak memerlukan pemrograman khusus untuk menampilkan jendela (window), dan cara penggunaannya juga berbasis visual seperti aplikasi windows yang lainnya, 


\section{CAHAYA PENDIDIKAN, 2(1): 21-33}

misalnya untuk mengatur besarnya jendela cukup untuk menarik form yang tersedia dengan mouse sehingga diperoleh ukuran yang dikehendaki.

Beberapa kemampuan dari Visual Basic 6.0 antara lain sebagai berikut :

1. Membuat program aplikasi berbasis window.

2. Membuat objek-objek pembantu program, misalnya File,Help dan sebagainya.

3. Menguji program dan menghasilkan program akhir yang langsung dapat dijalankan.

\section{Kondisi}

Dalam hampir semua program yang kompleks terdapat suatu penyeleksi kondisi. Dalam Visual Basic 6.0 penyeleksi kondisi menggunakan statement If.

a. Statement If

If digunakan untuk membandingkan suatu kondisi tertentu. Apabila If bernilai benar, maka ekspresi yang berada dalam blok If akan dijalanka, tetapi jika kondisi If salah, maka ekspresi yang berada dalam If tidak akan dijalankan.

Bentuk umum dari fungsi ini adalah sebagai berikut :

If (kondisi) Then

......(ekspresi)

End If

b. Statement If-Else 
If-Else digunakan untuk membandingkan suatu kondisi lebih dari satu. Apabila kondisi If bernilai benar, maka ekspresi yang berada dalam blok If akan dijalankan, tetapi jika kondisi If salah, maka ekspresi pada blok Else yang akan dijalankan.

Bentuk umum dari fungsi ini adalah sebagai berikut :

If (kondisi) Then

......(ekspresi-1)

Else

......(ekspresi-2)

End If

\section{PEMBAHASAN}

Kartu Perubahan Rencana Studi (KPRS) diperlukan untuk modifikasi kembali KRS bila terjadi kekeliruan, seperti adanya pembatalan, penambahan maupun penggantian mata kuliah. Sesuai dengan jadwal, modifikasi dilakukan setelah perkuliahan berjalan paling lama dua minggu. Algoritma berikut ditulis pada jendela kode yang muncul setelah melakukan klik ganda pada tombol proses.

Event klik dideklarasikan dengan mengetik perintah program Private sub cmdProses dan End sub, yang menunjukkan bahwa dengan mengklik tombol proses maka program KPRS akan dijalankan. Deklarasi variabel pada KPRS yang dimaksudkan untuk menentukan nama variabel beserta jenis dari variabel tersebut. Pendeklarasian variabel pada KPRS diletakkan dalam prosedur, sehingga variabel hanya digunakan oleh prosedur event pada KPRS. Pada algoritma ini dideklarasikan SKS, LOKAL, DIAM_KE, dan MAKS_SKS yang boleh diambil dengan jenis data Integer sedangkan IP_SEM_LALU dengan jenis data Single.

\section{Algoritma Deklarasi Event dan Variabel}

Algoritma ini berisikan tentang pendeklarasian event dan variabel pada form KPRS. 
Algoritma 1. Deklarasi Event dan Variabel

\begin{tabular}{|l|l|}
\hline $\begin{array}{l}\text { \% deklarasi event klik untuk tombol proses } \\
\text { [1] Private Sub cmdProses_Click() } \\
\text { \% deklarasi variabel dengan jenis data Integer } \\
\text { [2] Dim SKS, LOKAL, DIAM_KE, MAK_SKS As Integer }\end{array}$ \\
\hline
\end{tabular}

Algoritma Data Konstan dibuat agar kode fakultas atau program studi, semester dan tahun langsung tampil dalam form KPRS pada saat algoritma ini dijalankan.

Algoritma 2. Deklarasi Event dan Variabel

$$
\begin{aligned}
& \text { \% kode Fak/P>Studi pada text1 } \\
& \text { [4] Text1.text = “MIPA/MATEMATIKA" } \\
& \text { \% deklarasi semester pada text2 } \\
& \text { [5] Text2.text = "GENAP" }
\end{aligned}
$$

\section{Algoritma Baca Data}

Agoritma Baca Data bertujuan untuk membaca data yang diberikan (diinput dari keyboard), sehingga bila algoritma ini dijalankan data-data mahasiswa yang bersangkutan akan langsung ditampilkan pada form KPRS.

\section{Algoritma Baca Data Nomor BP}

Pada waktu algoritma atau program dijalankan, pengguna terlebih dahulu membaca data Nomor BP yang diberikan (diinput dari keyboard), sehingga nama mahasiswa yang bersangkutan akan langsung ditampilkan di dalam form KPRS. 
Algoritma 3. Baca Data Nomor BP

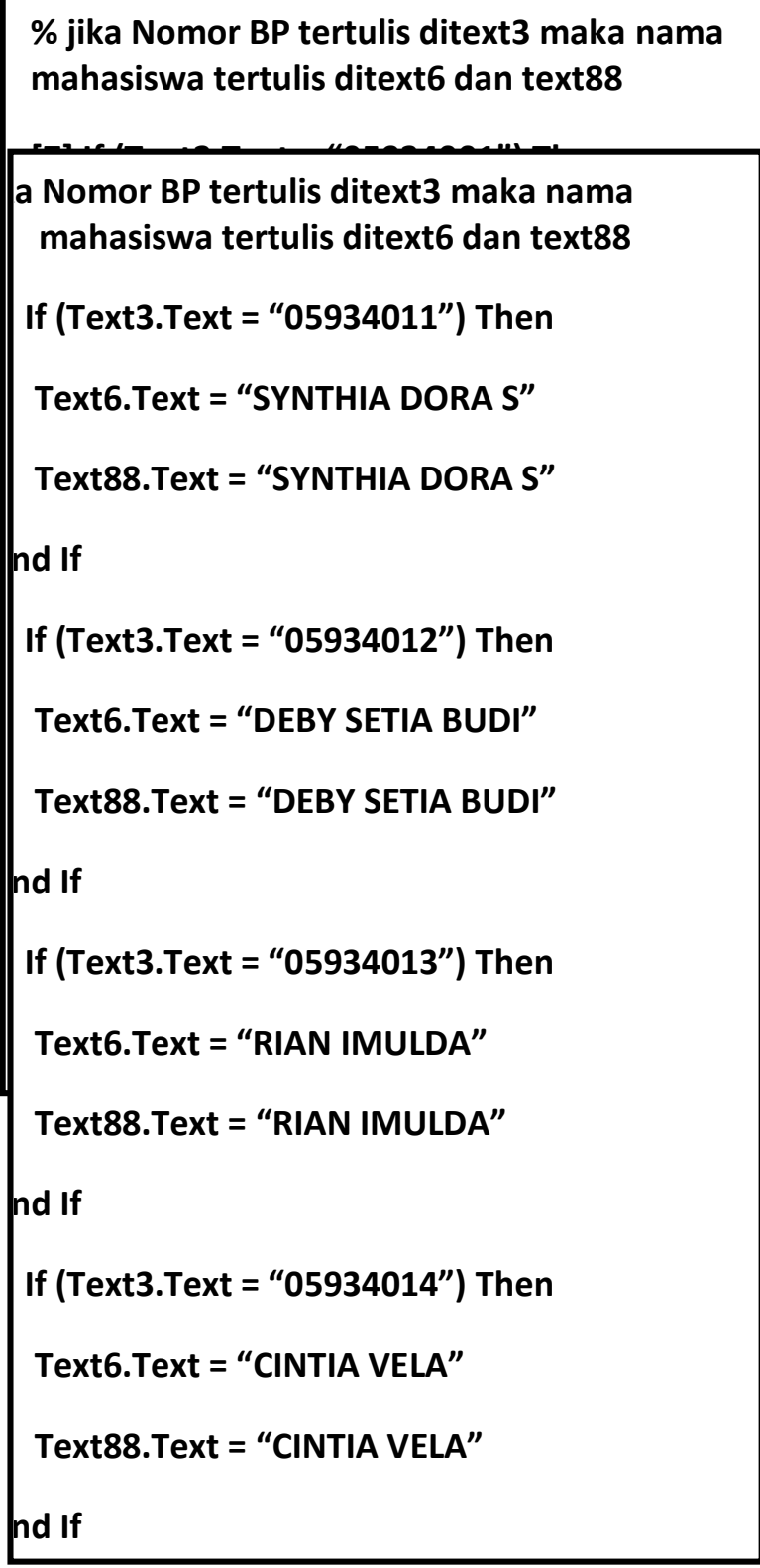

[12] If (Text3.Text = “05934006”) Then Text6.Text = "ILDA FITHIYANI"

[24] If (Text3.Text = “05934018") Then Text6.Text = "REFNI WIDIALISTUTI" Text88.Text = "REFNI WIDIALISTUTI" End If

[25] If (Text3.Text = “05934019”) Then Text6.Text = "MARTA HARIKAKAF"

Text88.Text $=$ "TANTI BERLIANA"

End If

[26] If (Text3.Text = “05934020") Then

Text6. Text = "TANTI BERLIANA"

Text88.Text $=$ "TANTI BERLIANA"

End If

[27] If (Text3.Text = “05934021") Then

Text6.Text = "ISTIQOMAH"

Text88.Text = "ISTIQOMAH"

End If

[28] If (Text3.Text $=$ “05934022") Then 


\section{Algoritma Baca Data Nama Mata Kuliah}

Pada waktu algoritma atau program dijalankan, pengguna terlebih dahulu harus memilih salah satu nama mata kuliah, sehingga kode mata kuliah, jumlah SKS dan lokal pengambilan mata kuliah tersebut akan langsung ditampilkan pada form KPRS.

Algoritma 4. Baca Data Nama Mata Kuliah

\% jika Nama Mata Kuliah dipilih pada Combo1, maka Kode Mata Kuliah, jumlah SKS dan lokal pengambilan mata kuliah langsung ditampilkan pada text.

[30] If (Combo1.Text = "KONSEP TEKNOLOGI") Then

Text8. Text = "PAM 112"

\% jika Nama Mata Kuliah dipilih pada Combo1, maka Kode Mata Kuliah, jumlah SKS dan lokal pengambilan mata kuliah langsung ditampilkan pada text.

[32] If (Combo1.Text $=$ "PENGANTAR APLIKASI KOMPUTER") Then

Text8.Text $=$ "PAM 182"

Text26. Text $=$ “3”

Text32. Text $=" 1 "$

[33] If (Combo1.Text $=$ "STATISTIKA ELEMENTER") Then

Text8.Text $=$ "PAM 192"

Text26. Text $=$ "4"

Text32. Text $=" 1 "$

[34] If (Combo1.Text = "FISIKA DASAR II") Then

Text8. Text $=$ "PAP 112"

Text26. Text $=$ “3”

Text32. Text $=" 1 "$

[35] If $($ Combo1.Text $=$ "PENDIDIKAN KEWARGANEGARAAN") Then
[42] [40] If (Combo1.Text $=$ "PEMROGRAMAN LINEAR") Then

Text8. Text $=$ "PAM 372"

Text26. Text $=$ "3"

Text32.Text $=" 1 "$

[43] If (Combo1.Text = "ALJABAR II")

Then

Text8. Text = "PAM 332"

Text26. Text $=$ “4"

Text32. Text ="1"

[441 If $($ Combo1.Text $=$ "PEMROGRAMAN LINEAR") Then

Text8.Text = "PAM 372"

Text26. Text $=$ "“3"

Text32.Text $=" 1 "$

[45] If (Combo1.Text = "ALJABAR II") Then

Text8.Text $=$ "PAM 332"

Text26. Text $=$ "4"

Text32. Text ="1" 
Algoritma Baca Data Kode Mata Kuliah ini terdiri dari Combo1 sampai Combo6 untuk matakuliah yang terdaftar, Combo13 sampai Combo15 untuk penambahan mata kuliah, dimana fungsi untuk memilih nama mata kuliah. Sedangkan combo7 sampai Combo12 dan Combo17 sampai Combo19 untuk memilih urutan pengambilan mata kuliah (diam-ke). Algoritma Combo1 dapat dilihat pada algoritma 3 diatas.

Setiap Combo memiliki nomor text yang berbeda, dimuat setiap text akan diisi pada kode mata kuliah, SKS, lokal dan diam-ke. Bila nama kode mata kuliah dipilih pada Combo1 maka pada text8 akan ditampilkan kode mata kuliah, pada text26 akan ditampilkan jumlah SKS 
mata kuliah tersebut, pada text32 akan ditampilkan lokal dengan angka " 1 " berarti pengambilan matakuliah tersebut untuk kelas pertama. Untuk Combo2, Combo Combo3 sampai Combo6 dan combo13 sampai Combo15 hasilnya akan ditampilkan sama seperti pada Combo1.

\section{Algoritma Mencari Jumlah SKS, SKS Keseluruhan dan Maks SKS}

Algoritma ini berisikan rumus untuk menghitung Jumlah SKS dan Jumlah SKS Keseluruhan serta logika untuk mencari Maks SKS.

Algoritma 5. Mencari Jumlah SKS, SKS Keseluruhan dan Maks SKS

\% rumus mencari Jumlah SKS dan Jumlah SKS Keseluruhan

[53] Text86.Text $=$ Val $($ Text50.Text $)+\operatorname{Val}($ Text51.Text $)+$ Val $($ Text52.Text $)+$ Val(Text53.Text)+ Val(Text54.Text)+ Val(Text55.Text)

Jumlah SKS = Val $($ Text86.Text $)$

[54] Text87.Text $=$ Val $($ Text86.Text $)+\operatorname{Val}($ Text80.Text $)+$ Val $($ Text81.Text $)+$ Val(Text82.Text)

Jumlah SKS Keseluruhan = Val(Text87.Text $)$

\% Jika IP semester lalu ditulis ditext4 maka Maks SKS tertulis ditext7

[55] If(Text4.Text<"1.5") Then Text7.Text = "12"

End If

[56] If(“1.5" $<=$ Text4. Text $<=1.99)$ Then Text7.Text $=$ "15"

\section{Algoritma Tombol Hapus}

Algoritma ini digunakan untuk menghapus data yang telah ditampilkan pada form, kemudian pada form akan tampil lembaran kososng yang siap untuk mengisi data baru.

Algoritma 6. Tombol Hapus

\% klik Hapus untuk menghapus data pada
form

[1] Text1.Text=""

[2] Text1.Text=""
[19] Text1. Text="",

29 [20] Text1. Text=""

[21] Text1.Text=""

[22] Text1.Text="" 


\section{Algoritma Tombol Print}

Algoritma tombol Print digunakan untuk mencetak form KPRS

Algoritma 7. Tombol Print

\% klik Print untuk mencetak KPRS

[38] Private sub CmdPrint_Click()

KDPC Drint Form

\section{Algoritma Tombol Keluar}

Algoritma tombol Keluar bertujuan untuk menutup form KPRS

Algoritma 8. Tombol Keluar

\% klik Keluar untuk menutup form KPRS

[39] Private sub CmdKeluar_Click()

Tmlond Man 


\section{Algoritma ComboBox}

ComboBox pada program ini berupa daftar nama mata kuliah dan daftar nama dosen jurusan Matematika.

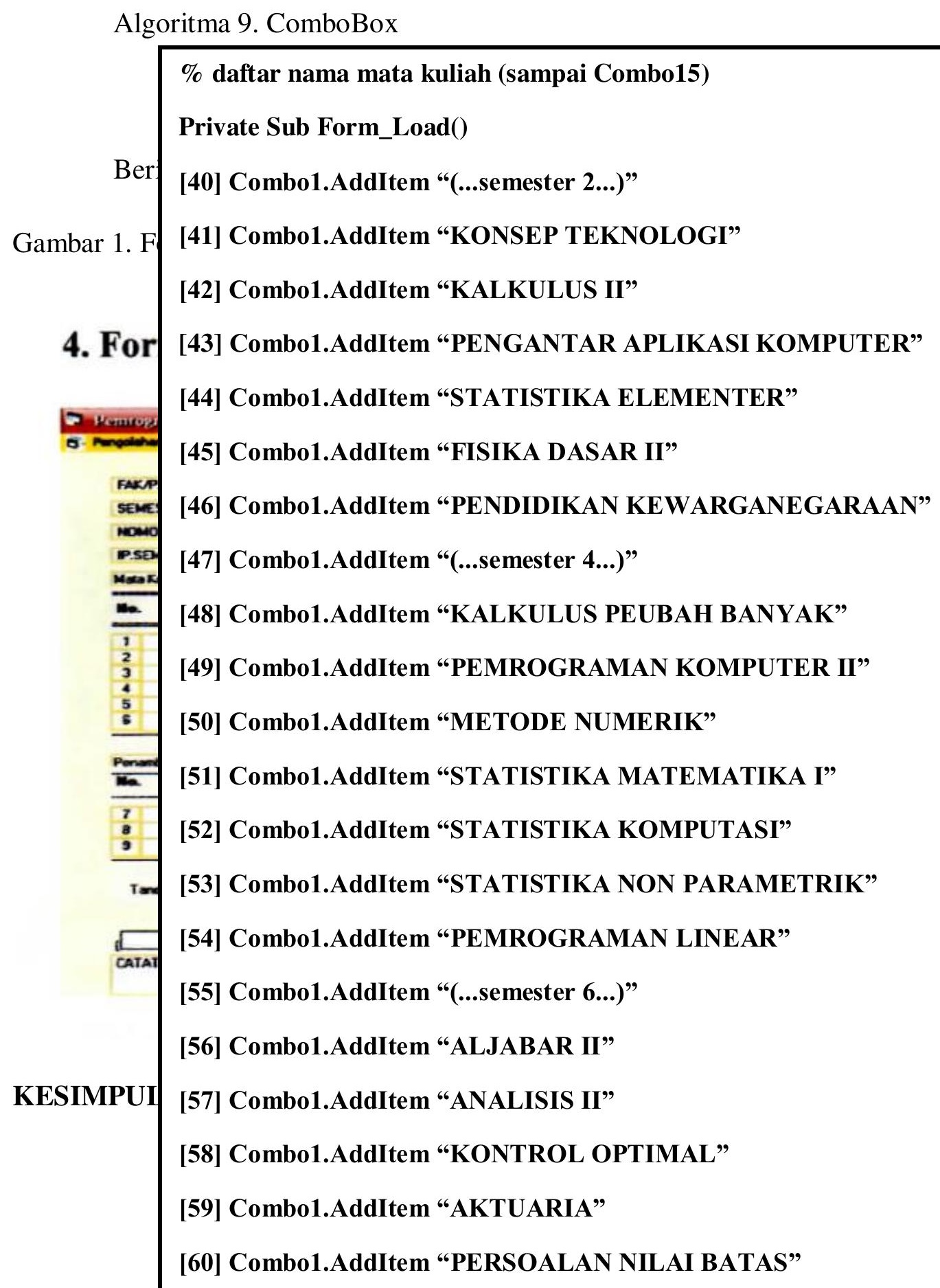


Form KPRS yang ditampilkan dengan menggunakan Visual Basic 6.0, sangat memberikan kemudahan bagi pengguna aplikasi ini. Hanya dengan menggunakan satu perintah atau dengan mengklik salah satu tombol, yaitu tombolproses, tombol hapus, tombol print dan tombol keluar, maka semua data yang dibutuhkan akan langsung ditampilkan pada masingmasing form. Semua tombol-tombol difungsikan dengan beberapa algoritma, yang mana pada algoritma tersebut telah diprogram untuk semua data yang dibutuhkan.

Dengan demikian kemungkinan adanya kesalahan data dan perhitungan akan sangat kecil, karena semua data telah diprogram sebelum ditampilkan kembali. Oleh karena adanya kemudahan-kemudahan seperti ini, keakuratan hasil data akan lebih terjamin.

\section{DAFTAR PUSTAKA}

Erhans, Dr. 2004. Membuat Program Inventaris Toko Dan Jasa Pendidikan dengan Microsoft Visual basic 6.0. Penerbit Ercontara Rajawali, Jakarta.

Halvorson, Michael. 2002. Step by Step Microsoft Visual Basic 6.0 Professional. Penerbit Elex Media Komputindo, Jakarta.

Razaq, abdul. 2004. Belajar Cepat Langsung Praktek Visual Basic 6.0. Penerbit INDAH Surabaya.

Tabrani, Suryanto. 1999. Aplikasi Akuntansi dengan Visual basic 6.0. Penerbit Elex Media Komputindo. 